\title{
EI campo léxico "mujer" en sajón antiguo y su aplicación a la Virgen María: ¿igualdad o selección?
}

\author{
Miguel AYERBE LINARES \\ Universidad del País Vasco/Euskal Herriko Unibertsitatea \\ miguel.ayerbe@ehu.es
}

Recibido: 16 de noviembre de 2011

Aceptado: 28 de enero de 2012

\section{RESUMEN}

En el presente artículo se trabaja con la siguiente hipótesis: la Virgen María fue una mujer, por un lado, como las demás, pues fue muchacha, mujer adulta, esposa y madre, como lo puede ser cualquier otra mujer. Ahora bien, por otro lado, el hecho de ser al mismo tiempo madre y permanecer virgen la dotaba de una distinción única y exclusiva. En este sentido, pensamos que esta distinción particular pudo tener su correspondiente repercusión lingüística en sajón antiguo, lo cual podría haberse materializado en el empleo o ausencia de determinados términos léxicos del campo léxico "mujer" a la hora de referirse a ella. Una explicación para este hecho podría fundamentarse en la necesidad de salvaguardar un contenido teológico delicado: la perpetua virginidad de María antes, durante y después de dar a luz a Cristo.

Palabras clave: Campo léxico, mujer, sajón antiguo, Virgen María, selección.

\section{The Lexical Field "Woman" in Old Saxon applied to the Virgin Mary: Equality or Discrimination?}

\begin{abstract}
In this article the following hypothesis is presented for discussion: The Virgin Mary was, on the one hand, a very normal woman, since she was a young girl, adult woman, wife and mother, like any other woman can be. In spite of that, on the other hand, the fact of being mother and remaining virgin at one and the same time provided her with a unique and exclusive distinction. According to this, we assume that this particular distinction could have linguistic consequences in Old Saxon by using or avoiding the use of certain lexical terms. A possible explanation for this could be found in the necessity of keeping an important theological doctrine free from any doubt: Mary's perpetual virginity before, during and after giving birth to Christ.
\end{abstract}

Keywords: Lexical Field, Woman, Old Saxon, Virgin Mary, Discrimination.

SUMARIO: 1. Introducción y antecedentes. 2. Objeto del presente trabajo y procedimiento seguido. 3. Muestras del campo léxico "mujer" recogidas para el estudio. 4. Análisis de muestras para cada término. 5. Conclusión. Referencias bibliográficas. 


\section{Introducción y antecedentes}

Los diferentes textos que nos han llegado en sajón antiguo contienen hasta cierto punto un amplio repertorio de términos léxicos para referirse a "mujer". Los referentes para estos términos son también muy variados, siendo empleados para hacer alusión tanto a mujeres en general, una mujer cualquiera, mujeres conocidas históricamente, mujeres conocidas bíblicamente, mujeres de mala fama, mujeres de buena reputación y, finalmente, también a la Virgen María.

Los términos constatados en esta lengua para referirse a "mujer" han sido, desde luego, objeto de estudio en diferentes artículos, si bien hay que puntualizar que el análisis que se lleva a cabo de los términos tiene lugar de modo individualizado y no en su conjunto o de forma global. Efectivamente, autores como Kögel (1892), Jostes (1893), Braune (1907a, b, c), Loewenthal (1917), Mezger (1942) y Nowicki (1977) se ocupan de analizar desde el punto de vista etimológico el significado y uso de términos concretos. Ahora bien, se echa en falta un estudio detallado que analice el campo léxico "mujer" en su conjunto dentro del ámbito sajón antiguo. Lo que más se le acerca es una miscelánea de Bosco, consistente en un artículo de revista en el que ofrece una visión panorámica de diferentes términos utilizados en todas las lenguas germánicas antiguas, de las que el sajón antiguo es una de ellas y a la que apenas se dedica dos páginas (1980: 277-278). Lo mismo se puede decir del capítulo introductorio de la obra de Weinhold en torno a las mujeres en la Alemania medieval (1851: 1-7). Este hecho contrasta abiertamente con la situación del alto alemán antiguo, donde nos encontramos con el extenso y detallado estudio de Koschkämper (1999). Allí cada uno de los términos es analizado con bastante profundidad, desde el punto de vista de su documentación (muestras / ocurrencias textuales), uso, función, procesos de formación de palabras, etc ${ }^{2}$. También existen estudios de tipo más especulativo, que tratan de poner nombre propio a un término empleado en el Hildebrandslied, objeto del trabajo de Meinecke (2003). En éste, la pregunta es si el término prut (Hildebrandslied 21) se refiere o no a la mujer legítima de Hildebrand.

Con todo, el propósito del presente trabajo no es llevar a cabo un estudio panorámico acerca del inventario de términos pertenecientes al campo léxico "mujer" en sajón antiguo. No queremos negar con ello el interés que podría tener tal propósito, así como la ayuda que proporcionaría ciertamente el hecho de contar con una visión panorámica y conjunta de este campo léxico. Ahora bien, nuestra intención aquí es otra.

\footnotetext{
${ }^{1} \mathrm{Al}$ objeto de evitar repeticiones innecesarias, más adelante presentaré una relación de los términos constatados en esta lengua para el campo léxico "mujer".

${ }^{2}$ Con todo, el estudio no es, en nuestra modesta opinión, exhaustivo, pues hay dos términos que no están incluidos en el análisis y que, sin embargo, están atestiguados en alto alemán antiguo: gimahha y thiu. Quede dicho, no obstante, que este estudio analiza también con igual detalle los términos pertenecientes al campo léxico "varón".
} 
Analizando este mismo campo léxico en alto alemán antiguo (Ayerbe 2011a) y el alto alemán medio (Ayerbe 2011b), pudimos constatar que había términos que se empleaban exclusivamente para referirse a la Virgen María y no para otras mujeres. También llegamos a constatar lo contrario, es decir, términos, que se utilizaban para cualquier mujer salvo para la Virgen María. Llamaba especialmente la atención que el hecho de que algunos términos nunca se utilizaran para referirse a la Virgen María no se debía precisamente al comportamiento y consideración moral de una mujer concreta, pues podíamos comprobar sin lugar a dudas que, sin embargo, se usaban para referirse a mujeres de buena reputación e, incluso, piadosas.

Todo ello nos llevó a sospechar que quizá podría haber por parte de los autores de los correspondientes textos en alto alemán antiguo la intención de salvaguardar a nivel expresivo o lingüístico un trasfondo teológico delicado: María es mujer, esposa y madre pero, al mismo tiempo, virgen. Todos estos atributos se podían, y se pueden, predicar por separado y sin problemas de cualquier mujer, pero predicarlos todos simultáneamente de una única mujer sólo era posible en relación con la Virgen María, en virtud de un privilegio especial de Dios. Según ese privilegio, María fue verdadera madre conservando al mismo tiempo su virginidad ${ }^{3}$. La sospecha de la que hablábamos unas líneas más arriba parece encontrar, además, apoyo en un comentario de Braune (1907b: 33) en el que, hablando del término usado para referirse a san José en alto alemán antiguo, afirma "So ist in einer Reichenauer glosse zu Matth. 1, 16 Joseph virum Mariae das wort virum Gl. 1, 708, 27 mit gimahelon glossiert, weil er nach der correcten theologischen auffassung nur ihr verlobter war". En este punto, nos vemos obligados a objetar que José, según la correcta teología, no fue el "prometido" de María -como parece afirmar Braune-, sino su verdadero marido y esposo. María y José no fueron simplemente prometidos o novios, sino que constituyeron un verdadero matrimonio, si bien no hubo cohabitación carnal, pues José, siguiendo la misión que Dios le había encomendado en relación con María, fue el guardián de su integridad como virgen (Arroyo 1968: 431s.; Bastero 1995: 217). Ahora bien, no obstante nuestra objeción, la afirmación de Braune deja abierta la puerta a la hipótesis de que en alto alemán antiguo podía darse en autores de diferentes textos la intención de distinguir lingüísticamente en algunos contextos muy concretos a la Virgen María de las demás mujeres, incluso de las de mejor fama y más piadosas, como por ejemplo, Isabel, la madre de san Juan Bautista.

Esta hipótesis se confirmó en nuestro estudio previo en alto alemán antiguo (Ayerbe 2011a), llegando a delimitar en concreto: a) qué términos se empleaban tanto para la Virgen María como para otras mujeres; b) qué términos se utilizaban para referirse exclusivamente a la Virgen María; c) qué términos se evitaban para referirse exclusivamente a otras mujeres. Algo parecido podemos afirmar, a raíz de un estudio similar, acerca del alto alemán medio (Ayerbe 2011b).

${ }^{3}$ Cfr. Catecismo de la Iglesia Católica, (1992) §§ 490-493. 


\section{Objeto del presente trabajo y procedimiento seguido}

Tras lo dicho en el apartado anterior, nuestro propósito es aplicar ahora el mismo tipo de análisis a la terminología concerniente al campo léxico "mujer" empleada en textos compuestos en sajón antiguo. En concreto, se trata de comprobar hasta qué punto también en esta lengua se pueden constatar diferencias en el uso de términos léxicos, según sea la referencia la Virgen María u otra mujer. ¿Hay términos que sean empleados exclusivamente para referirse a la Virgen María?, ¿hay términos cuyo uso se evita por algún motivo para hacer alusión a la Virgen María? Estos son los dos interrogantes que nos formulamos en el presente trabajo.

Para ello, partimos de la misma hipótesis que para el análisis del campo léxico "mujer" en alto alemán antiguo: dado el carácter excepcional de la Virgen María en cuanto virgen y madre a la vez, se pretende dejar claro en los textos que María no fue madre ni virgen en el mismo sentido que cualquier otra mujer que haya sido esposa y madre o, por el contrario, virgen, lo cual llevaría a que dicha distinción encontrara su expresión también en los textos escritos, mediante el lenguaje.

Con este fin, procedimos en primer lugar a la recogida términos léxicos pertenecientes al campo léxico "mujer" en una serie de textos compuestos en sajón antiguo, que relacionamos a continuación ${ }^{4}$ :

1) Heliand, según la edición de O. Behaghel, continuada por B. Taeger.

2) Genesis, según la edición de O. Behaghel, continuada por B. Taeger.

3) Las Glossae Lipsianae, según la edición de M. Heyne.

4) El fragmento de una homilía de Beda, según la edición de M. Heyne.

5) Las Eltener Glossen zu Mattceus, según la edición de E. Wadstein.

6) Las Essener Evangeliarglossen, según la edición de E. Wadstein.

Tras la recogida de muestras léxicas, se elaboró un corpus en el que se consignaba junto con cada muestra si el término en cuestión se empleaba para referirse genéricamente a "mujer" o si se usaba para referirse a una mujer concreta. En este último caso se consignaba también el tipo de mujer concreta o el nombre propio, si éste se daba a conocer.

A continuación se trató de constatar si había términos que sólo fuesen utilizados para referirse a la Virgen María. Después de esto se llevó a cabo la operación contraria, es decir, comprobar si había términos cuyo empleo no se constatara para referirse a la Virgen María. Durante el desarrollo de estos dos pasos se tuvo especial cuidado en buscar contextos o situaciones similares en los que, por un lado,

\footnotetext{
${ }^{4}$ Las fuentes textuales aquí relacionadas no agotan la producción textual conocida en sajón antiguo. Hay, efectivamente, más textos que fueron analizados pero que, finalmente, no fueron tenidos en cuenta en el presente estudio, debido a que no ofrecían muestras relevantes pertenecientes al campo léxico que aquí se analiza.
} 
apareciera la Virgen María y, por otro lado, otra mujer. Estos contextos eran, concretamente, aquellos que se referían a una u otra mujer en su papel de "esposa", "madre" y "virgen". Pensábamos que sería en estos tres contextos donde podrían darse diferencias en cuanto a la elección de términos léxicos, según fuera la Virgen María u otra mujer la referencia para un término determinado.

\section{Muestras del campo léxico "mujer" recogidas para el estudio}

De los textos arriba mencionados hemos obtenido un total de 181 muestras de términos pertenecientes al campo léxico "mujer". Dichas muestras fueron localizadas siguiendo dos métodos de rastreo: en el primero de ellos nos servimos del localizador léxico que ofrece el Thesaurus Indogermanischer Text- und Sprachmaterialien (T.I.T.U.S.) ${ }^{5}$; ahora bien, como en este banco de textos no están aún incluidos todos los textos existentes en sajón antiguo, en algunos de ellos tuvimos que realizar el rastreo de forma clásica o tradicional, es decir, leyendo íntegramente los textos y anotando por nuestra cuenta las muestras que fuéramos hallando. Como es obvio, este segundo método era más lento que el primero, pues el banco de textos electrónico realiza el rastreo y presenta las muestras halladas a una velocidad incomparablemente más alta. Ahora bien, en la búsqueda con ayuda del banco de textos tuvimos que poner especial cuidado en introducir cada lexema con las diferentes formas de flexión que podía tener en sajón antiguo, pues el buscador léxico del banco de textos distingue entre formas flexivas.

En cuanto al inventario en sí de términos diferentes para hacer alusión al campo léxico "mujer", en los textos analizados hemos hallado los siguientes, por orden alfabético y mostrando todas las formas gráficas y flexivas atestiguadas:

1) brûd, brûdi, brûdiu, brûdiun

2) fêmea, fêhmia

3) frî, frîho, frîo

4) frûon

5) gimehlidun

6) hîuuon, hîuun

7) idis, idise, idisi, idiso, idison, idisio, idisiu

8) magad, magađ

9) quân

${ }^{5}$ Accesible en Internet en la dirección: http://titus.uni-frankfurt.de/indexs.htm?/index2.htm\#Dstart (última consulta: 28 de septiembre de 2011). 
10) quena, quene, quenun

11) thiorna, thiorne, thiornon, thiornun

12) thiu, thiuu, thiumuon, thumue, thumuon

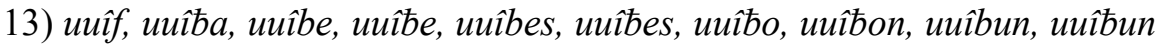

En cuanto a la frecuencia de aparición de cada término, véase la siguiente relación:
1) brûd
11
2) fêmea
2
3) $f r \hat{\imath}$
4) frûa
5) gimehlidun
6) hîuua

2
7) idis
8) magað
9) quân
10) quena
11) thiorna
12) thiu 6
13) uutff 70

\section{Análisis de ocurrencias para cada término}

En la siguiente fase del estudio se procedió a analizar las muestras recogidas, con un doble fin de fondo: por un lado, comprobar los rasgos semánticos propios en función de la mujer a la que se refiere en concreto; por otro lado, observar si su uso comprende también a la Virgen María, la excluye o sólo se refiere a ella. Para la mayoría de los términos analizados se presenta una selección de citas textuales, al objeto de no extendernos excesivamente en la exposición de los resultados con ejemplos parecidos o repetitivos. Dichas citas constituyen muestras representativas acerca del uso y rasgos semánticos de los términos aquí estudiados. 


\subsection{Brûd}

Todas las muestras recogidas, si bien tienen como referentes a una gran variedad de mujeres, tienen también un rasgo semántico común, presente en todos los casos: tratarse de una mujer legítimamente casada. También es común a todas ellas, a excepción de tres casos, haber sido ya madres. Ejemplos de ello encontramos en las citas siguientes:

1) [...] siu ni uuelde thera engilo / lêra lêstian (that uuas Loðas brûd), [...] (Genesis 331-332). Referencia a la mujer de Lot.

2) [...] siðor ic sie mi te brûdi gecôs. (Heliand 147). Isabel, mujer de Zacarías y madre de san Juan Bautista.

3) [...] thoh ni mohta im gio sêrara dâd / uuerðan an thesaro uueroldi, uuîtun managun, / brûdiun an Bethleem: [...] (Heliand 747-749). Las madres de los Santos Inocentes asesinados por Herodes.

4) [...] bûide imu be theru brûdi, thiu êr sînes brôđer uuas, [...] (Heliand 2706). Alusión a Herodías, esposa de Filipo, hermano de Herodes.

5) Hie thero is brûdi bigann, / thera idis opanlîco unhiuri fî̀nd uuunder tôgian, [...] (Heliand 5442-5444). Referencia a la esposa de Pilatos.

En cuanto a las tres excepciones de las que hablábamos más arriba, que no hayan sido madres en el momento en el que se habla de ellas no quiere decir que hubiera algún impedimento, sino que la ausencia de hijos era solamente circunstancial:

6) Thô uuarð hugi Iosepes, / is môd giuuorrid, the im êr thea magað habda, / thea idis anthêttea, aðalcnôsles uuîf / giboht im te brûdiu. (Heliand 295-298). Referencia a la Virgen María.

7) Ni uuelda sia imo te brûdi thô, / halon imo te hîuuon, [...] (Heliand 301-302). Alusión a la Virgen María.

8) thar scolda man êna brûd geban, [...] (Heliand 1996). Referencia a la recién casada en las bodas de Caná.

Como se puede comprobar, en las citas 6 y 7 la Virgen María aún no había tenido tiempo de dar a luz, pero no queda la menor duda de que llegó a ser madre poco más tarde. En cuanto a la cita 8 , sucede algo parecido: la mujer que estaba celebrando su boda, al estar recién casada, es asumible que tampoco haya tenido tiempo aún de tener hijos?

\footnotetext{
${ }^{6}$ Cfr. Evangelio de San Lucas, II, 1-12.

${ }^{7}$ La Sagrada Escritura no nos dice nada acerca de si esta mujer en concreto tuvo o no descendencia posteriormente, sin embargo, este hecho no cierra la puerta a la posibilidad de que más adelante los tuviera.
} 


\subsection{Fêmea}

Las dos únicas referencias con las que contamos se refieren a la Virgen María y a María Magdalena, con el significado de "mujer recatada, entregada, devota, afectuosa":

9) [...] ni uuas gio thiu fêmea sô gôd, [...] (Heliand 310). Alusión a la Virgen María.

10) [...] uuelda ina mid iro mundon grîpan, / thiu fêhmia an thena folko drohtin, [...] (Heliand 5931-5932). Referencia a santa María Magdalena.

En la cita 9) es donde mejor se puede contextualizar el significado del término, pues aparece en un momento delicado para la Virgen María: José se ha dado cuenta de que María espera un hijo, en cuya concepción él no ha intervenido. No duda de que en dicha concepción haya habido una intervención divina, ni de que María siga siendo una mujer sin tacha, sin embargo, los pensamientos que tiene acerca de si debe o no separarse de ella se deben a que no sabe qué papel le corresponde a él mismo en todo lo que sucede y que, quizá, deba quitarse de en medio para no estorbar los planes de Dios para ella. El autor del Heliand, con el objetivo de resaltar claramente y dejar a salvo la integridad de María, utiliza el término fêmea para acentuar que no cabía la menor duda acerca de la integridad personal de María, pues entre todas las mujeres que pueblan la tierra no se podría encontrar una más íntegra, devota, fiel y entregada, como esposa, que ella. Otro tanto podría decirse de María Magdalena en la cita 10): una discípula tan fiel y tan devota de Jesucristo, que se alegra en extremo por la resurrección de éste.

\subsection{Frî}

Este término hace referencia a una mujer en general, sin hacer especial hincapié en ningún rasgo semántico concreto, como "esposa", "madre", "prometida", "doncella", etc. Por este motivo, el término se emplea tanto para referirse a mujeres en general como a una mujer en concreto:

11) [...] endi hietun thô gangan thanan, / firrian ina fon them fiundum endi lêdian is frî mið im, [...] (Genesis 293-294). Referencia a la esposa de Lot.

12) [...] that siu simbla thana bedskepi buggean scolda, / frî mid ira ferhu: [...] (Heliand 309-310). Referido en general al castigo reservado para toda mujer que cometiera adulterio.

13) Fôdda ina thô fagaro frîho scâniosta, [...] (Heliand 438). Alusión a María como la más hermosa y agraciada entre todas las mujeres.

14) Thô ni uuas lang te thiu, / that it sân antfunda frîo scôniosta, / Cristes môder: [...] (Heliand 2016-2018). De nuevo María, como la más extraordinaria y hermosa entre todas las mujeres, esta vez en el episodio de las bodas de Caná.

15) Sô thiu frî habdun / gegangan te them gardon, [...] (Heliand 5794-5795). Alusión a las devotas Mujeres que acudieron al sepulcro donde había sido sepultado Jesucristo tras morir en la Cruz. 
16) [...] all uuurðun fan them grurie / thiu frî an forahton mikilon, [...] (Heliand 5812-5813). Nueva alusión a las mujeres que acudieron al sepulcro, apenadas por la muerte de Jesucristo.

\subsection{Frûa}

La única muestra encontrada se encuentra en el fragmento de una homilía de Beda, en el que la Virgen María es tratada con una elevada dignidad como Señora:

17) Sô he it imo thô iegivan habda, sô wîeda he it an úses drohtines êra endi úserô frûon sanctae Marîun endi allerô Cristes martirô, [...] (4-6).

Aquí la Virgen María recibe un tratamiento muy respetuoso, propio de la veneración con que se acudía a la Virgen María, ya elevada en cuerpo y alma al Cielo. El término no ha sido constatado para referirse a otra mujer, lo cual tampoco quiere decir que en la lengua hablada no se hubiera utilizado para referirse a cualquier otra mujer a la que se quiere mostrar respeto y dignidad. Simplemente, no hemos hallado más muestras.

\subsection{Gimehlida}

Este término se emplea para referirse técnica y legalmente a una mujer unida en legítimo matrimonio. El significado preciso en español sería "cónyuge". En los textos analizados sólo han sido encontradas dos muestras, y éstas se refieren a la Virgen María como esposa legal de san José:

(18) coniugem tuam: gimehlidun thina (Eltener Glossen zu Matthcus 27 $)$

(19) coniugem: gimehlidun (Essener Evangeliarglossen 31 ${ }^{\mathrm{b}}$ )

El término aparece en el pasaje en el que el ángel se aparece a san José, justo en medio de sus dudas acerca de si debe o no separarse de María a la vista de la concepción de Jesucristo, para tranquilizarle y confirmarle en su misión de ser el legítimo esposo de María y padre putativo de la criatura que aquélla porta en sus entrañas. El ángel acentúa aquí que no debe temer llevar consigo a María, porque ella es su verdadera esposa. Resulta aquí llamativo que en este caso se utilice, para referirse a María como esposa, un término distinto del que se usa para otras mujeres, que también son esposas legítimas. Ello podremos comprobarlo más adelante.

\subsection{Hîuua}

También este término se emplea para una mujer en el significado de "mujer casada". Dos muestras hemos hallado en los textos:

20) Ni uuelda sia imo te brûdi thô, / halon imo te hîuon, [...] (Heliand 301-302). Referencia a la Virgen María.

21) [...] that brôđer brûd an is bed name, / hebbie sie imu te hîuun. (Heliand 27132714). Alusión a Herodías, la mujer de Filipo. 
En el primer caso, el término hîuua no se usa para María en sentido propio, pues lo que expresa el texto es la resistencia de José -el ángel aún no se le ha aparecido para tranquilizarle y aclararle la situación- a tomar a María como esposa, por lo que se puede deducir que en ese momento María aún no era a todos los efectos civiles la esposa de José ${ }^{8}$. En el segundo caso, san Juan Bautista está amonestando a Herodes por intentar casarse ilegítimamente con la que es esposa de su hermano Filipo.

\subsection{Idis}

El uso de esta palabra en sajón antiguo es muy amplio, no sólo por el número de muestras recogidas sino también, y sobre todo, por la diversa tipología de mujer a la que puede hacer referencia. Así, se puede hallar empleado para una mujer cualquiera en general:

22) [...] that that ni môsta forlattan negên / idis undar Ebreon, [...] (Heliand 454-455)

También para una mujer casada:

23) Ôc scal ic iu seggean noh, / huuô it thar an them aldon êo gebiudid, / that ênig erl ôdres idis ni bisiunîca, [...] (Heliand 1475-1477)

Para una mujer viuda que ha sido madre:

24) Thiu môder aftar geng / an iro hugi hriuuig endi handun slôg, / carode endi cûmde iro kindes dôđ, / idis armscapan; [...] (Heliand 2183-2186). Referencia a la viuda de Naín.

Para una mujer anciana:

25) [...] hiet that ic thi thoh gicûðdi, that thi kind giboran, / fon thînera alderu idis oddan scoldi / uuerðan an thesero uueroldi, [...] (Heliand 123-125). Alusión a Isabel, esposa de Zacarías.

Para una madre en general:

26) Thar imu tegegnes quam / ên idis fan âdrom thiodun; [...] / siu bad thene craftagan drohtin, / hêlagna, that he iru helpe gerêdi, quað that iru uuâri harm gistanden, / soroga at iru selberu dohter, [...] (Heliand 2984-2985, 2986-2988). Episodio de la mujer cananea que intercede por su hija.

\footnotetext{
${ }^{8}$ De hecho, el Evangelio de San Mateo (I, 18) apunta que José nota la concepción de Jesús por parte de María antes de que diera comienzo la convivencia de los esposos conforme a la ley judía. A partir de ese momento José se plantea si debe repudiar en secreto a María.
} 
Para una mujer adúltera:

27) [...] thiu idis uuas bifangen / an farlegarnessi, [...] (Heliand 3842-3843). Episodio de la mujer adúltera tratada con misericordia por Jesucristo.

Para una doncella / mujer pura:

28) Thô uuarð is uuisbodo / an Galilealand, Gabriel cuman, / engil thes alounaldon, thar he êne idis uuisse, [...] (Heliand 249-251). Referencia a la Virgen María justo antes de la Anunciación.

29) Grôtta hie thuo Ioahnnes, hiet that hie iru fulgendi uuel, / minniodi sia sô mildo, sô man is muoder scal, / idis unuиamma. (Heliand 5617-5619). Jesús, colgando desde la cruz, deja a su madre santa María al cuidado de su discípulo Juan.

Para una mujer piadosa y llena de gracia:

30) [...] thu bist thînun hêrron liof, / uualdande uuirðig, huuand thu giuuit haちes, / idis enstio fol. (Heliand 259-261). Palabras dirigidas por el arcángel Gabriel al saludar a la Virgen María.

\subsection{Magað}

El uso de este término está claramente dirigido a una mujer joven, una muchacha que, además, es soltera y virgen:

31) [...] thar he êne idis uisse, / munilîca magað: Maria uuas siu hêten, [...] (Heliand 251-252). Episodio en el que el arcángel Gabriel va en busca de la Virgen María para anunciarle que ha sido elegida para convertirse en la Madre de Dios.

32) [...] Maria endi Martha, magað frîlîca, [...] (Heliand 3967). María y Marta, hermanas de Lázaro, a quien Jesucristo había resucitado. Los tres gozaban de gran amistad con él.

33) Thô uиarð thera magað aftar thiu môd gihuorben, / hugi aftar iro hêrron, [...] (Heliand 2760-2761). Referencia a la hija de Herodías, cuando va a salir a bailar ante los convidados de Herodes.

34) [...] ef he sie tan hêti lî́u binimen, / thea magað fur theru menegi, [...] (Heliand 3860-3861). Episodio de la mujer adúltera.

35) [...] endi thô te themu thegne sprac / magađ unuuânlîc: [...] (Heliand 49564957). Referencia a la criada del Sumo Sacerdote que increpa a san Pedro justo antes de las negaciones.

En términos generales, puede concluirse que magað se utilizaba para referirse a una mujer joven y virgen, tal como se constata en antiguo alto alemán (Ayerbe 2011). Ahora bien, su uso en dos contextos parece presentar algunas dificultades, en lo que se refiere a la inclusión del rasgo semántico "virgen": por un lado, al referirse en varias ocasiones a la hija de Herodías en una actitud frívola en el baile 
ante los comensales de Herodes parece poner en entredicho el rasgo semántico "virgen". No obstante, esta duda se presenta únicamente en un plano ante todo moral, pues el hecho de que salga a deleitar con su danza a los convidados de Herodes, si bien puede hablar de un comportamiento de cierta frivolidad y provocativo, éste no implica que la muchacha haya dejado de ser virgen en su cuerpo. Más complicado se presenta, por otro lado, el empleo de magað para referirse a la joven sorprendida en adulterio (cita número 34). A raíz de ello, tan sólo podríamos concluir entonces que magað se emplea para una mujer joven y, muy probablemente, también soltera, pero no para una virgen.

Por otro lado, en cuanto al rasgo semántico "soltera", quizá podría presentar el uso de este término para la Virgen María en el verso 386 del Heliand cierta dificultad. El contexto es el siguiente: María ha dado a luz a Jesucristo en la gruta de Belén. María y José son ya esposos y conviven -si bien esta convivencia excluye totalmente las relaciones sexuales entre ellos-, por lo que el uso aquí de magað, en su matiz de mujer soltera, no sería ya apropiado para ella.

A pesar de todo, la explicación que podemos ofrecer aquí sería, no obstante, la siguiente: magað se emplea aquí expresamente para recalcar que María sigue siendo virgen, e insistir claramente en ello, a pesar de que legalmente ha dejado de ser soltera y de que acaba de ser madre. Dicho con otras palabras, el uso de magað aquí estaría justificado para salvaguardar en este preciso contexto que María no ha perdido la virginidad debido a la maternidad. Si, en lugar de éste, se hubiera empleado otro término, el aspecto de la virginidad, de enorme trasfondo teológico, quedaría demasiado difuso. Todo ello a pesar de su uso también para referirse a la mujer sorprendida en adulterio, una mujer ciertamente joven que ha perdido su virginidad. Con todo, en este último caso es evidente que magað es empleado en el significado de mujer joven $\mathrm{y}$, muy probablemente, soltera, pero excluyendo la virginidad perdida. En este sentido, magað se está empleando aquí para referirse simplemente a la "joven" o "muchacha" que fue sorprendida en adulterio, pero no a una "virgen", estrictamente hablando.

Por estas razones, nos inclinamos a considerar que la matriz semántica de $m a$ gað en sajón antiguo incluía, a pesar de las dificultades arriba expuestas, los rasgos "joven", "soltera" y "virgen". Otra cuestión es que se plantee el interrogante acerca del motivo por el que el autor del Heliand utiliza magað en el contexto de la mujer adúltera, aunque sea para referirse simplemente a "la joven" sin más, que en ese preciso momento ya no podía ser virgen, pudiendo sembrar así confusión. De hecho, constituye el único caso excepcional entre las muestras recogidas para $\mathrm{ma}$ gað en sajón antiguo ${ }^{9}$. Pero esta cuestión nos llevaría a desviarnos del tema principal de nuestro trabajo y, por ello, nos vemos obligados a dejarla para otro análisis. Desde luego, se puede proponer la hipótesis de que magað tenía una matriz semántica que, sin duda, incluía el rasgo semántico "virgen intacta", pero al mis-

\footnotetext{
${ }^{9}$ Quede, además, constancia de que parientes del término magað en otras lenguas germánicas, como el godo y el alto alemán antiguo, hacen alusión de forma inequívoca a una virgen en el sentido propio de la palabra, como equivalentes de $\pi \alpha \rho \theta \varepsilon ́ v o \varsigma$ en griego y de virgo en latín, respectivamente.
} 
mo tiempo no se reducía a este rasgo semántico, sino que incluía también el de "mujer joven, muchacha" en términos generales y sentido amplio. Estas aparentes contradicciones parecen estar poniendo de manifiesto, por tanto, que magað podía tener tanto un referente genérico tal como "muchacha, joven", como otro referente más específico, según el contexto, que sería el de la "muchacha virgen". En cualquier caso, debe quedar claro que el uso de magað en alusión a la adúltera no significaba "prostituta", sino simplemente "muchacha, joven". Dicho en otras palabras, el uso de magað en este episodio, para hacer alusión a la mujer que había cometido adulterio, no porta el significado de "prostituta", sino el de "muchacha, joven". De ahí que hablemos sólo de "aparentes contradicciones". De no haber sido así, está claro que se daría una clara contradicción al comprobar su uso tanto para referirse a la mujer adúltera como a la Virgen María. Ahora bien, ninguna incompatibilidad surge de la convivencia de los rasgos semánticos "virgen", por un lado, y "mujer joven, doncella", por otro. Otro asunto bien distinto es que una mujer, además de ser joven o muchacha, manifieste conductas frívolas (como es el caso de la hija de Herodías) o se cometa adulterio.

\subsection{Quân}

La única muestra que hemos podido encontrar se refiere a Isabel, la mujer de Zacarías, justo en el momento en el que queda embarazada tras el anuncio de que, a pesar de su avanzada edad, concebirá y dará a luz un hijo:

36) Thô uuarð sân aftar thiu maht godes, / gicûðid is craft mikil: uuarð thiu quân ôcan, [...] (Heliand 192-193)

A falta de más muestras para este término, carecemos de elementos de contraste, así como de fundamento para poder observar regularidades en su empleo. En este sentido, es difícil sacar conclusiones acerca de su uso. Tan sólo podemos concretar, para este caso, que la mujer a la que quân hace alusión está casada y va a ser madre.

\subsection{Quena}

Para este término contamos con tres muestras, una de las cuales aparece en unas glosas para traducir el término latino uxor, que significaba "esposa, mujer casada" a todos los efectos:

37) quena $=$ uxor (Glossae Lipsianae 735,5)

En los dos otros casos, el término quena se emplea para dos mujeres distintas, ambas casadas y también madres:

38) Thô imu that unîf ginam / the cuning te quenun; [...] (Heliand 2708-2709)

39) Thô uuas êndago allaro manno / thes uuîsoston, thero the gio an thesa uuerold quâmi, / thero the quene ênig kind gibâri, [...] (Heliand 2785-2787) 
En la cita número 37 la mujer a la que se hace referencia es a Herodías, esposa de Filipo, arrebatada ilegítimamente por Herodes. Ésta había sido ya madre, cuya hija fue la muchacha que bailó ante los invitados de Herodes. En la cita siguiente, la mujer en cuestión es Isabel, esposa de Zacarías y madre de san Juan Bautista. Así pues, se da la coincidencia de que el término quena se utilizaba para referirse a una mujer casada, que también es madre o está en camino se serlo.

\subsection{Thiorna}

Este término, sensiblemente más atestiguado que los dos anteriores, nos permite comprobar que su uso se dirige a mujeres que están libres de compromiso matrimonial, bien porque aún no se han casado, bien porque después de un tiempo de matrimonio han quedado viudas, volviendo, por tanto, al estado de doncellez. La edad no juega aquí un papel decisivo, pues encontramos una muestra empleada para referirse a la profetisa Ana, mujer anciana que en sus años de juventud estuvo casada con un hombre que murió tras siete años de matrimomio ${ }^{10}$ :

40) Siu môsta aftar ira magaðhêdi, sîðor siu mannes uuarð, / erles an êhti eðili thiorne, [...] (Heliand 507-508)

En el resto de muestras, las mujeres aludidas son la Virgen María (14 veces), la hija de Herodías (3 veces) y, finalmente, unas doncellas en general (1 vez). Ahora bien, si en el caso de su uso para la hija de Herodías no presenta dificultades -pues de ésta, aparte de su juventud, no consta que estuviera casada ni prometida-, sí parece hacerlo en el caso de María. El término se usa para aludir a ella, no sólo antes de convivir con José, sino también una vez que ya están juntos. No obstante, un análisis más detallado de las muestras de thiorna para referirse a María llama la atención sobre el hecho de que con frecuencia el término venga acompañado de los adjetivos hêlag y sâlig, con el significado de "bienaventurada, piadosa, dichosa", así como del substantivo godes como complemento del nombre. Muy probablemente, el uso de este término referido a la Virgen María no esté sino buscando resaltar su doncellez o virginidad, aun dentro del matrimonio. María es una mujer que se conserva intacta, no sólo en su alma sino también en su cuerpo, no obstante su condición de mujer legítimamente casada con José. Esto concuerda, desde luego, con la vocación particular de María, quien por un privilegio especial y exclusivo por parte de Dios, había de ser esposa, madre y, simultáneamente, virgen:

41) Gifrang aftar thiu / eft an ôðrun daga aðalcunnies unîf, / sâlig thiorna, that he undar them gisî̇ia ni uuas. (Heliand 800-802). Referencia a la Virgen María.

42) [...] filu gornoda / thiu godes thiorna. (Heliand 805-806). Alusión a la Virgen María.

${ }^{10}$ Cfr. Evangelio de San Lucas, II, 37. 
43) Than thoh gitrûoda siu uuel / an iro hugiskeftiun, hêlag thiorne, [...] (Heliand 2028-2029). Alusión a la Virgen María.

44) [...] unt that im eft mahtig god, / hêr hebanes uuard iro hugi buotta, / that im uurðun ôdana erebiuuardos, / thegnos endi thiornun, [...] (Genesis 101-104). Alusión a unas doncellas en general.

\subsection{Thiu}

Este término es el que menos problemas plantea a la hora de su clasificación semántica y funcional, a pesar del reducido número de muestras. Efectivamente, el significado de este término está muy ligado a una mujer en el papel de una sirvienta o, incluso, sierva. En concreto, las «Glossae Lipsianae» dan testimonio de la traducción del término latino ancilla al sajón antiguo como thuuue, thuuuon, thiuuuon $(935,2-4)$. El resto de muestras recogidas insisten en el valor semántico de servicio, o de estar subordinado a alguien:

45) Thiu bium ic theotgodes. (Heliand 285). Precisamente el pasaje en el que María se declara "esclava" de Dios tras el anuncio del arcángel ${ }^{11}$.

46) Thar quam im ên fêkni uuîf / gangan tegegnes, thiu ênas Iudeon uuas, / iro theodanes thiuu, [...] (Heliand 4954-4956). Alusión a la sirvienta que dirige la palabra a san Pedro en la escena de las negaciones.

47) [...] that sô lioநen man lêð gistôdi, / that he sô hônlîco hêrron sînes / thurh thera thiuun uuord, thegno snellost, / farlognide sô liobes: [...] (Heliand 5026-5028). Referencia a la misma sirvienta.

\subsection{Uuîf}

Este término debía contar con una matriz de rasgos semánticos muy reducida, lo cual le permitía ser empleado para un amplio número de referencias posibles. En este sentido, el rasgo semántico esencial de este término sería "ser humano de sexo femenino". Efectivamente, uuîf aparece para designar a cualquier tipo de mujer, conocida o no, de cualquier edad, estado social y civil:

48) [...] deda is uuîf sô self [...] (Heliand 78). Alusión a Isabel, esposa de Zacarías y mujer de avanzada edad.

49) Thô quam thar ôc ên uuîf gangan / ald innan them alaha: [...] (Heliand 503-504). Alusión a la profetisa Ana en la escena de la Presentación de Jesús en el templo ${ }^{12}$. Dicha mujer era viuda y de avanzada edad.

50) [...] endi thô te themu uuîbe sprac; [...] (Heliand 2747). Referencia a la joven hija de Herodías, en el momento en el que Herodes le pide que baile ante sus invitados.

\footnotetext{
${ }^{11}$ Cfr. Evangelio de San Lucas I, 38: Dixit autem Maria: "Ecce ancilla Domini; fiat mihi secundum verbum tuum".

${ }^{12}$ Cfr. Evangelio de San Lucas II, 36: "Et erat Anna prophetissa, filia Phanuel, de tribu Aser. Haec processerat in diebus multis et vixerat cum viro annis septem a virginitate sua; $[\ldots]$ ”.
} 
51) [...] aðalcnôsles uuîf [...] (Heliand 297). Alusión a la noble estirpe de la que procedía la Virgen María.

52) Thô uuarð eft thes uuîbes hugi / aftar them ârundie al gihuorben / an godes uuilleon. (Heliand 281-283). Nueva alusión a la Virgen María en la escena de la anunciación por parte del arcángel, como joven virgen.

53) Thô gihôrde that friðubarn godes / uuillean thes uuîtes endi sprak iru mid is uuordun tô: / 'uuela that thu uuîf haظes uuillean gôden!' (Heliand 3022-3024). Referencia a la mujer cananea, una madre que implora ayuda para su hija poseída por los demonios.

54) Thar quam im ên fêkni uuîf / gangan tegegnes, [...] (Heliand 4954-4955). Alusión a una sirvienta.

55) [...] huat sie scoldin themu uuîbe duan, [...] (Heliand 3847). Alusión a la mujer sorprendida en adulterio.

56) Than uuas eft gihêlid hugi / iungron Cristes, thuo sia gihôrdun thiu guodun uuîf I mârian thia maht godes; (Heliand 5892-5894). Referencia a las piadosas mujeres que reciben y transmiten la noticia de la resurrección de Cristo.

57) Siu ni mohta thuo hofnu auuîssan, / that uuîf ni mahta uuôp forlâtan: [...] (Heliand 5917-5918). Alusión a santa María Magdalena.

58) [...] huand thar uuas gumono gitald / âno uuîf endi kind, uuerodes atsamme / fif thûsundig. (Heliand 2870-2872). Alusión a mujeres en general en el episodio de la multiplicación de los panes y los peces ${ }^{13}$.

59) That uuîf uuard thuo an forahton, / suiðo an sorogon, [...] (Heliand 54495450). Referencia a la esposa de Pilato.

\section{Conclusión}

Tras el análisis de las muestras recogidas, se puede comprobar que, efectivamente, existe una distinción en el uso de determinados términos según sea una u otra la mujer a la que se hace referencia. En concreto, se puede concluir que hay términos que se emplean tanto para la Virgen María como para otras mujeres: brûd, frî, frûa ${ }^{14}$, idis, magad, thiorna, thiu y uûff; al mismo tiempo, se constata un término para hacer alusión exclusivamente a la Virgen María: gimehlida, para hablar de ella como cónyuge en contextos parecidos en los que otras mujeres son designadas como quân o quena; por último, se constatan términos para referirse a cualquier mujer salvo la Virgen María: hîuua, quân y quena. Curiosamente, estos

\footnotetext{
${ }^{13}$ Cfr. Evangelio de San Mateo XIV, 13-21.

${ }^{14}$ Como ya se ha dicho antes, este término sólo ha sido constatado una vez para referirse a la Virgen María, pero, por su significado, nada impide que se pudiera emplear -ni que de hecho se emplease en la lengua hablada- para dirigirse a cualquier otra mujer en actitud de sumisión, servicio, veneración, respeto, etc. Por este motivo, lo hemos incluido aquí.
} 
dos últimos términos, precisamente para referirse a una mujer como esposa o mujer casada, no se utilizan para María, del mismo modo que gimehlida -también como cónyuge- sólo se utiliza para ésta y no para cualquier otra mujer casada. A raíz de esta distinción terminológica, existen indicios para pensar que hay un rasgo de la mujer legítimamente casada que se quiere poner a salvo especialmente en el caso del matrimonio de María y José: siendo legítimos y verdaderos esposos, ello no implicaba la cohabitación carnal, lo cual permite dejar a salvo a nivel expresivo la perpetua virginidad de María, aun siendo madre. En cuanto a los términos brûd y hîua, se usan en un contexto referido a la Virgen María, pero para indicar más bien con claridad lo que no ocurrió, es decir, que la Virgen María concibiera y diera a luz con el concurso de José, como una mujer común. De hecho, ambos términos aparecen en el contexto en el que José se resiste a hacer a María su esposa en el sentido común y extendido de la palabra en su época ${ }^{15}$.

En otras palabras, en aquellas situaciones y en aquellos contextos en los que María no se distinguía esencialmente de otras mujeres, se emplean para ella los mismos términos que para otras mujeres (idis, magað, uuîf, etc.). En cambio, como fue esposa - pero de forma distinta a otras mujeres, excluyendo la cohabitación carnal-y como fue madre -pero no como las demás mujeres, pues lo fue sin intervención de varón y preservando intacta su virginidad-, ambos aspectos había que expresarlos lingüísticamente para hacer alusión a ella de forma distinta a como se hacía para cualquier otra mujer, pues de lo contrario se podía correr el riesgo de difuminar en extremo la perpetua virginidad de María, llevando a una peligrosa confusión a los receptores de los textos. En cambio, con la distinción terminológica se hacía posible llamar de algún modo la atención sobre el hecho de que María era singular respecto de las demás mujeres en cuanto al matrimonio, la maternidad y la virginidad.

Antes de terminar, quedaría añadir que los resultados alcanzados aquí coinciden con los obtenidos anteriormente en el estudio del campo léxico "mujer" en alto alemán antiguo (Ayerbe 2011). Efectivamente, y como se apuntaba más arriba, también en alto alemán antiguo se constata una cuidadosa selección de términos para referirse a una mujer como esposa o cónyuge, según sea el referente la Virgen María o cualquier otra mujer. De hecho, se puede mencionar como ejemplo de ello que el término que se utiliza exclusivamente para hacer alusión a María como esposa frente a otras cónyuges es -con las naturales diferencias grafemáticas y fonéticas- muy parecido: gimehlida en sajón antiguo y gimahha en alto alemán antiguo. Dicho término no se emplea, como decimos, para referirse a otras mujeres exactamente en la misma condición de "cónyuge, esposa". Finalmente, esta coincidencia en alto alemán antiguo y en sajón antiguo deja abierta la puerta a posteriores análisis de esta misma cuestión en otros ámbitos lingüísticos germánicos como el gótico, el inglés antiguo y el nórdico antiguo, los cuales podría ser interesante llevar a cabo.

\footnotetext{
${ }^{15}$ Véase de nuevo las citas 6 y 7.
} 


\section{Referencias bibliográficas}

\section{Fuentes textuales:}

BEHAGHEL, O. (ed.), Heliand und Genesis. 10. Überarbeitete Auflage von B. TAEGER. Tubinga: Max Niemeyer 1996.

«Bruchstück der Übersetzung einer Homilie Bedas», en: HEYNE, M. (ed.), Kleinere altniederdeutsche Denkmäler. Paderborn: Ferdinand Schöningh 1877, 65-66.

«Eltener Glossen zu Mattæus», en: WADSTEIN, E. (ed.), Kleine altsächsische Sprachdenkmäler. Norden / Leipzig: Diedr. Soltau's 1899, 46-47.

«Essener Evangeliarglossen», en: WADSTEIN, E. (ed.), Kleine altsächsische Sprachdenkmäler. Norden / Leipzig: Diedr. Soltau's 1899, 48-61.

«Glossae Lipsianae», en: HEYNE, M. (ed.), Kleinere altniederdeutsche Denkmäler. Paderborn: Ferdinand Schöningh 1877, 41-59.

Sagrada Biblia. Vol. 5: Nuevo Testamento. Texto latino, traducción y notas. Pamplona: EUNSA 2004.

\section{Bibliografía secundaria:}

ARROYO, A., La Virgen María. Madrid: B.A.C. 1968.

AYERBE, M., «¿Hay diferencias en el uso de términos del campo léxico “mujer” en textos del Alto Alemán Antiguo?», Estudios Franco-Alemanes 3 (2011a). (En prensa).

AYERBE, M., «Aportaciones de la literatura alemana medieval a la determinación léxica en la traducción del alto alemán medio: aplicación al campo léxico 'mujer'», en: LÓPEZ FOLGADO, V. (ed.), Essays on Translation. Hamburgo: Dr. Kovač 2011b. (En prensa).

BASTERO, J. L., María, Madre del Redentor. Pamplona: EUNSA 1995.

BOSCO, M., «Donna, moglie nei principali dialetti germanici antichi», Aevum 54:2 (1980), 257-279.

BRAUNE, W., "Zur altsächsischen Genesis», Beiträge zur Geschichte der deutschen Sprache und Literatur 32 (1907a), 1-29.

BRAUNE, W., «Nhd. Braut in den germanischen Sprachen», Beiträge zur Geschichte der deutschen Sprache und Literatur 32 (1907b), 30-59.

BRAUNE, W., «Nachträge zu Braut», Beiträge zur Geschichte der deutschen Sprache und Literatur 32 (1907c), 559-562.

JOSTES, F., «Idis», Indogermanische Forschungen 2 (1893), 197-198.

KÖGEL, R., «Idis und Walküre», Beiträge zur Geschichte der deutschen Sprache und Literatur 16 (1892), 502-508.

KOSCHKÄMPER, B., «Frau» und «Mann» im Althochdeutschen. Fráncfort del Meno: Peter Lang 1999.

LA IGLESIA CATÓLICA, Catecismo de la Iglesia Católica. $2^{\text {a }}$ edición. Vaticano: Libreria Editrice Vaticana 1992.

LOEWENTHAL, J., «as. idis», Arkiv för nordisk filologi 33 (1917), 131.

MEZGER, F., «The formation of Old High German diorna, Old Saxon thiorna, Gothic widuwairna, and Old English níwerne», Modern Language Notes 57 (1942), 432-433.

MEINECKE, E., «prut in bure barn unwahsan. Hiltibrants Frau und ihr Kind», en: HEIZMANN, W. / NAHL, A. von (ed.), Runica Germanica Medievalia. Berlín: de Gruyter 2003, 430-453.

NOWICKI, H., "Ahd. As. Thiorna», Zeitschrift für Deutsches Altertum und Deutsche Literatur 106:2 (1977), 83-87.

WEINHOLD, K., Die deutschen Frauen in dem Mittelalter. Viena: Carl Gerold 1851. 